no one infringed a neighbouring airway. In a terminal area I am sure accuracy is much higher, because it needs to be. Airway widths vary from one country to another and are unimportant and the boundaries are not evident to pilots, who try to stay not within the arbitrary boundaries but not too far from the centre line. The area just outside the official airway is just as safe and good as the airway, and indeed safer than the centre line where traffic density is highest and only an altitude mistake by controller or pilot is needed to promote a collision-natural dispersion is still safer than extreme accuracy. Crews generally fly only as accurately as necessary, reserving their energy for the most important tasks: the study of Strumble shows adequate accuracy. Incidentally routes and airways should follow the curved path of aircraft instead of the right-angled bends, for instance the standard inbound route to Gatwick : Lydd-Cliff-Mayfield.

\title{
REFERENCE
}

1 White, A. (1971). Air traffic control separation standards and navigation. This Journal, 24, 443.

\section{The Knife as a Compass}

\section{Fischer Heinesen}

WHEN our Norwegian ancestors wished to navigate in the open sea they could find their bearings by the Sun or stars if the sky was not overcast. In foggy weather they used the sollarsteinn or sunstone, 'a stone with which one could see where the sun was in the heavens'. A knife blade will do equally well as may be seen from Fig. I. If you place the point of the knife on your thumb nail, as shown in the figure, on a sunny day you can easily see the shadow it casts; turning the blade a little one way or the other the shadow widens, but when the knife edge points towards the sun the shadow is reduced to a narrow line.

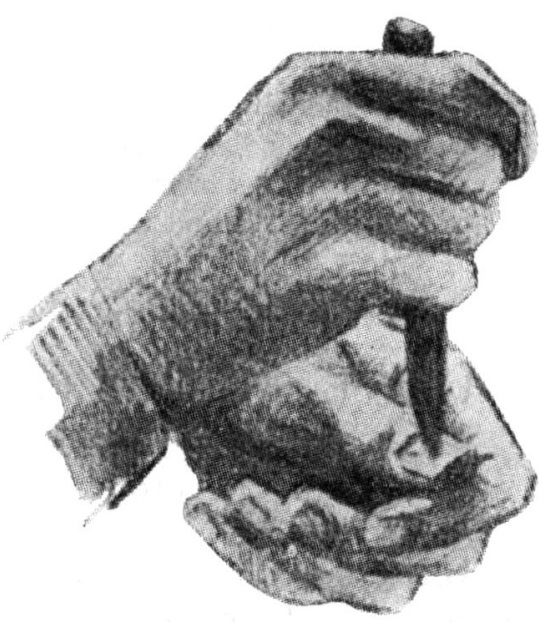

FIG. 1 . 
Now if the sky is overcast, or even in fog, rain or snow, the shadow of the knife can still be clearly seen although it is fainter; in fact it almost disappears when the knife edge is directly in line with the Sun. Knowing the direction of the Sun from a shadow, and knowing the time of day, you can find true North. Conversely, of course, one can find the time of day from the direction of the Sun, as one formerly did with sundials.

Our ancestors had no wrist watches, but even after several days at sea and in foggy weather we all have a built in timepiece if we use our instincts properly, although for the man with a wrist watch it may soon get out of order. I have heard a completely blind man say 'switch on the wireless, the news will be here in a minute', and he was quite right ! Our ancestors could at least check their time sense twice a day, at sunrise and sunset, and many of them could probably judge the time within a quarter of an hour. This would give Sun bearings correct to about $4^{\circ}$ in the Faroe Islands (where I live) in latitude $62^{\circ} \mathrm{N}$. The error would in fact be less than $3 \frac{1}{2}^{\circ}$ with the Sun on the prime vertical and not more than $5 \frac{1}{2}^{\circ}$ at noon.

In earlier times they did not sail in winter and during the short summer nights they might reasonably expect the wind to continue from the same quarter. Even if the wind did change they would note the direction of the swell. The knife method will also give the bearing during twilight, if the Sun is not more than about $6^{\circ}$ below the horizon. On voyages from Norway across the North Atlantic to Iceland and Greenland landfalls were often made on Shetland or the Faroes, so that at midsummer Sun bearings could usually be taken with a knife at almost any hour.

The method seems formerly to have been in common use in the Faroes and is described in the Foringatidende for April $189 \mathrm{I}$. I have also seen it described in some private papers, where the knife was not placed on the thumb nail but held up before the eyes. Few people seem to know anything about it now, though I met one Englishman who had heard of it but knew of no written description. In the Faroese language we still have a proverb Knivleysir madur er lívleysir, 'a knifeless man is a lifeless man'.

Another wrinkle for steering a boat under oars in calm foggy weather was to stream a line astern from a fishing rod. By keeping an eye on the rod they could tell if they were keeping a steady course, and check the course at intervals with the knife since the rod would not show slow changes. I have heard of a fishing rod being used effectively in this way in 19 I 2 when the crew had forgotten to take the compass on board with them. 